\title{
FOUR CASES OF ACUTE ACQUIRED HAEMOLYTIC ANAEMIA IN CHILDHOOD TREATED WITH A.C.T.H.
}

\author{
BY \\ B. S. ROSE and S. N. NABARRO \\ From the General Infirmary, Leeds
}

(RECEIVED FOR PUBLICATION, NOVEMBER 25, 1952)

In the early years of the present century the French school of haematologists appreciated that acute acquired haemolytic anaemia was dependent upon the presence of abnormal antibodies in the blood (Chauffard, Troisier and Vincent, 1908; Hayem, 1908; Widal, Abrami and Brulé, 1907).

During the first world war this important work was largely forgotten. Although Lederer (1925, 1930) gave his first classical description of the clinical picture in 1925 , it was not until 1940 that Dameshek and Schwartz (1940) again stressed the immunological aspects of the disease. More recently, improved technical methods (Dacie and de Gruchy, 1951) have made possible the demonstration of abnormal antibodies in many cases in which gross agglutination is absent, thus confirming the early studies. The reason for the development of these abnormal antibodies is still obscure, but an infective origin for acute acquired haemolytic anaemia has long been postulated. This theory has recently received some support from the work of Hagberg (1952). He was able to demonstrate considerable diminution in the survival time of normal red cells transfused into children suffering from apparently simple post-infective anaemia.

The knowledge that A.C.T.H. and cortisone interfere with antibody reactions has given fresh significance to these findings. During the last two years numerous reports (Best, Limarzi and Poncher, 1951; Crary and Beck, 1952; Dameshek, 1950; Dameshek, Rosenthal and Schwartz, 1951; Dameshek and Rosenthal, 1951; Davidson, Duthie, Girdwood and Sinclair, 1951 ; Etess, Bassen, Litwins and Sussman, 1951; Gardner, 1950; Gardner, McElfresh, Harris and Diamond, 1951; Langeron, 1951; Ley and Gardner, 1951; Mallarmé, Martin, Eyquem and Fleury, 1951; Meyer, 1951; Rosenthal, Spaet, Goldenberg and Dameshek, 1952; Unger, 1951; Young, Christian and Izzo, 1951) have dealt with the use of these drugs in the treatment of acute acquired haemolytic anaemia. Formerly, Dameshek and Schwartz (1940) drew attention to the value of splenectomy when blood transfusion alone was proving to be inadequate.

Four cases of acute acquired haemolytic anaemia were admitted to hospital during a period of 16 days in March, 1952. The weather at the time was cold and damp. All four children lived in Leeds; two (H.S. and J.G.) in adjacent streets of a modern estate four miles from the centre of the city; one (V.E.) in a poor district three miles distant from the hospital; and the fourth (V.P.) on the outskirts of the city, some six miles from the other children. None of the children attended the same school, nor had any contact with the others before this illness.

Because of the poor response to blood transfusions of three of these children (V.E., J.G. and H.S.) it was decided that A.C.T.H. should be tried.

\section{Clinical Summaries}

Case 1. V.E., a girl, aged 6 months, had no relevant family or personal history of previous illness. She was admitted with two days' history of pallor, cough and fretfulness. On examination, she was collapsed, pale and slightly icteric, with severe cough and dyspnoza. The pulse rate exceeded 140 per minute and the temperature was $101 \cdot 2^{\circ} \mathrm{F}$. There was no clinically detectable enlargement of liver, spleen or lymph nodes, and no haemorrhages were found. The retinae were normal. Numerous râles were present in all areas of the lungs. Subsequent $x$-ray examination showed multiple opacities, most marked at the left apex. Haemoglobinuria, absent on admission, developed at the time of a relapse which took place during the eighth to tenth weeks in hospital.

The blood count on admission showed haemoglobin $12^{\circ}$. (Sahli), red cells 790,000 per c.mm., colour index $0 \cdot 89$, leucocytes 17,200 per c.mm. (polymorphs $53^{\circ}$, metamyelocytes $5 \%$, myelocytes $1 \cdot 5^{\circ}$, lymphocytes $38^{\circ}$, basophils $2 \cdot 5^{\circ} \%$ ) and nucleated red cells 8 per 100 white cells.

The red cells showed moderate anisocytosis and marked polychromasia. There was a moderate neutrophilia with a shift to the left in the Arneth count. No 
primitive cells were seen and the platelets were normal. The bone marrow showed intense normoblastic hyperplasia, with no evidence of leukaemia. The serum bilirubin level was $2.2 \mathrm{mg}$. per $100 \mathrm{ml}$., and there was an excess of urobilinogen in the urine. Warm and cold autoagglutinins and warm iso-agglutinins were present during the active phase, making cross-matching difficult on several occasions. A severe relapse occurred after each of five transfusions. The baby was therefore given A.C.T.H., to which she responded well. On withdrawal of the drug she rapidly relapsed, and it was decided that splenectomy should be performed during a second course of A.C.T.H., as three further transfusions had been necessary. The splenectomy had no apparent effect, and she relapsed again when A.C.T.H. was withdrawn for the second time. A third course of A.C.T.H., later changed to cortisone, has therefore been given, and on this occasion, on withdrawal, 28 weeks after the onset of the illness, there has been no relapse. The direct Coombs test has remained positive from the outset, but is now only weakly positive. The early progress and treatment are shown in Fig. 1, and the results of virus studies in the Table.

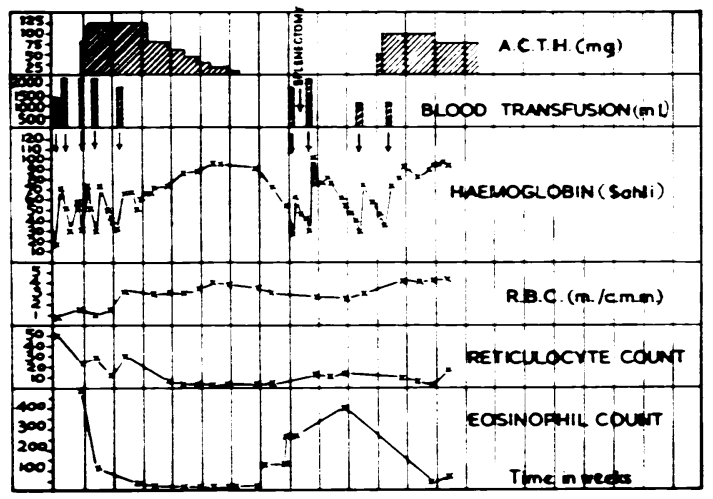

FIG. 1.

Case 2. H.S., a girl, aged 3 years, had no relevant family or personal history of previous illness. She was admitted with one week's history of listlessness, which in the last two days had become extreme, culminating in coma. She had been vomiting for 24 hours, and had passed red urine on the day before admission. On examination, she was comatose and extremely pale, with air hunger and gross retinal haemorrhages but no other evidence of bleeding. She was afebrile. There was no clinically detectable enlargement of the liver, spleen or lymph nodes. There were no significant signs in the chest, and subsequent $x$-ray examination proved to be normal. Gross haemoglobinuria was present during the first two weeks in hospital.

The blood count on admission showed: Haemoglobin 21\% (Sahli), red cells $1 \cdot 3 \mathrm{~m}$. per c.mm., colour index $1 \cdot 3$, leucocytes 31,800 per c.mm. (polymorphs $64^{\circ}$, metamyelocytes $8 \%$, myelocytes $1^{\circ}$ o, lymphocytes $36 \%$ ) and nucleated red cells 20 per 100 white cells.
The blood film showed a reactive leuco-erythroblastic picture, with no evidence of leukaemia. The platelets were normal. Marrow biopsy was not performed. The serum bilirubin level was $2.6 \mathrm{mg}$. per $100 \mathrm{ml}$., and the faecal urobilinogen $268 \mathrm{mg}$. per $100 \mathrm{~g}$. There was an excess of urobilinogen in the urine. The results of the initial Coombs test are unfortunately not available, but tests in the fourth and twelfth weeks were negative. Warm auto- and iso-agglutinins were present during the first week, and warm and cold iso-agglutinins were still readily detectable in the sixth week. As the child relapsed rapidly after each of three transfusions and remained desperately ill, A.C.T.H. was given over a period of five weeks. She responded well, and there has been no subsequent relapse. The Coombs test remained negative. The early progress and treatment are shown in Fig. 2.

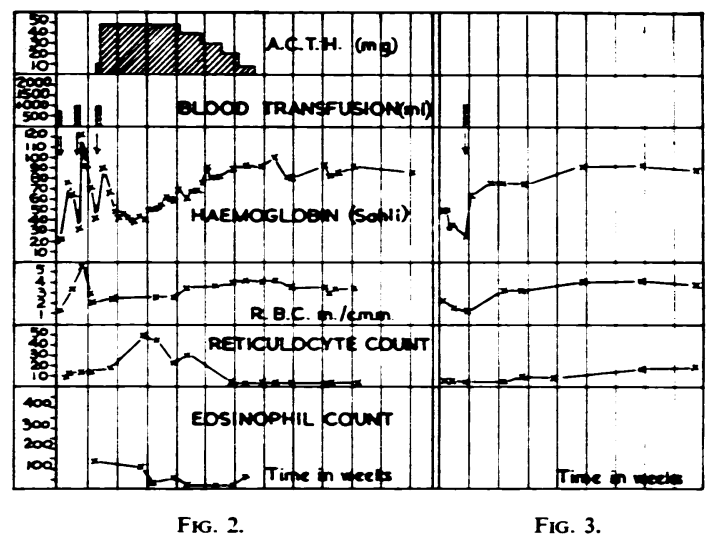

Case 3. V.P., a girl, aged 8 years, had no relevant personal or family history of previous illness. A sister who had a mild influenzal type of illness at the time of the patient's admission was examined shortly afterwards, and found to be normal. V.P. was admitted with three days' history of fever, lassitude, vomiting and slight epigastric pain. Three hours before admission she was noted to be dyspnoeic and extremely pale. On examination, she was found to be very pale, with slight icterus. She was febrile $\left(103 \cdot 6^{\circ} \mathrm{F}\right.$.) and dyspnoeic, with enlarged soft nodes in the neck, axillae and groins. The spleen was hard and extended three inches below the costal margin. The liver was abnormally firm and was felt one inch below the costal margin. There were a few petechiae in the conjunctivae and palate. The retinae were normal. Findings on physical and radiological examination of the chest were normal. No haemoglobinuria occurred.

The blood count on admission showed: Haemoglobin $50^{\circ}$ (Sahli), red cells $2 \cdot 3 \mathrm{~m}$. per c.mm., colour index $1 \cdot 09$, leucocytes 2,700 per c.mm. (polymorphs $29^{\circ}$, monocytes $12^{\circ}$, lymphocytes $59^{\circ}$ ).

The haemoglobin dropped to $28^{\circ}$ o within six days of admission. The blood film showed normal red cell morphology, and there was no evidence of leukaemia. Platelets were normal. Marrow biopsy showed normoblastic hyperplasia. The serum bilirubin level was 1-2 
mg. per $100 \mathrm{ml}$., and the faecal urobilinogen $248 \mathrm{mg}$. per $100 \mathrm{~g}$. Unfortunately, the original Coombs and serum agglutination tests are not available. There has been no relapse following a single blood transfusion, given on the seventh day after admission, and the child remains well despite persistent hepato-splenomegaly. The direct Coombs test was positive in the eighteenth week of her illness, but subsequently became negative. The early progress and treatment are shown in Fig. 3.

Case 4. J.G., a boy, aged 8 years, had no relevant family or personal history of previous illness. He was admitted with 14 days' history of fever, listlessness and pallor, which had become much worse during the last four days. He had passed dark urine, and had become jaundiced during the two days preceding admission. On examination, he was found to be extremely pale and jaundiced, with moderate enlargement of the spleen, liver and lymph nodes. There was no fever. There were no haemorrhages, and the retinae were normal. Findings in the chest were normal, and subsequent $x$-ray examination was negative. Gross haemoglobinuria was present during the first three weeks, and again during a relapse in the ninth and tenth weeks.

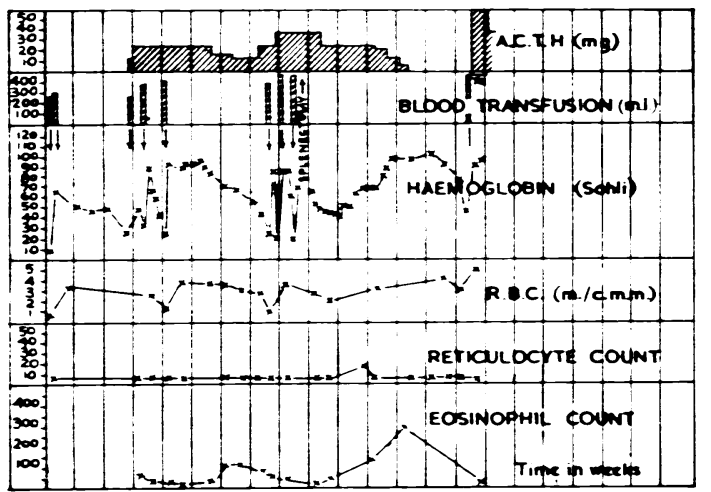

FIG. 4.

The blood count on admission showed: Haemoglobin $19^{\circ}$ (Sahli), red cells $1.05 \mathrm{~m}$. per c.mm., colour index 0.93 , leucocytes 28,000 per c.mm. (polymorphs $66 \%$, metamyelocytes $3^{\circ} \mathrm{o}$, myelocytes $1^{\circ}$, monocytes $2^{\circ}$, lymphocytes $28^{\circ} \mathrm{o}$ ) and nucleated red cells 117 per 100 white cells.

The blood film showed many haemoglobinized normoblasts, macroreticulocytes and microspherocytes. The platelets were normal. There was no evidence of leukaemia. Marrow biopsy was not performed. The serum bilirubin level was $3 \cdot 2 \mathrm{mg}$. per $100 \mathrm{ml}$., and the faecal urobilinogen was $630 \mathrm{mg}$. per $100 \mathrm{~g}$. There was gross excess of urobilinogen in the urine. A.C.T.H. was given to this child in view of severe relapses following each of five transfusions. He responded well to A.C.T.H., but relapsed following withdrawal. After three further transfusions had been given splenectomy was performed, but this had no apparent effect on the course of his illness. A second course of A.C.T.H. was therefore given, to which he again responded. In the seventeenth week after admission cortisone was substituted for A.C.T.H. to enable him to continue treatment at home. One further attempt at withdrawal resulted in brisk haemolysis, and he still requires $75 \mathrm{mg}$. of cortisone daily, 30 weeks after the beginning of his illness.

The direct Coombs test was repeatedly positive, but became negative during the thirteenth week while he was receiving A.C.T.H. It again became positive during the last relapse, and still has not reverted to negative after 30 weeks. The early progress and treatment are shown in Fig. 4.

\section{Epidemiological Considerations}

In view of the comparative rarity of acute acquired haemolytic anaemia, and of its suspected association with infection, it was considered that these cases might represent the effect of an epidemic of some known infective disease. Paul-Bunnell and Widal tests in all four cases were negative. Serum from each case was cultured for virus, with negative results. Agglutination tests for the atypical pneumonia group were carried out by the Central Virus

TABLE

COMPLEMENT FIXATION TESTS

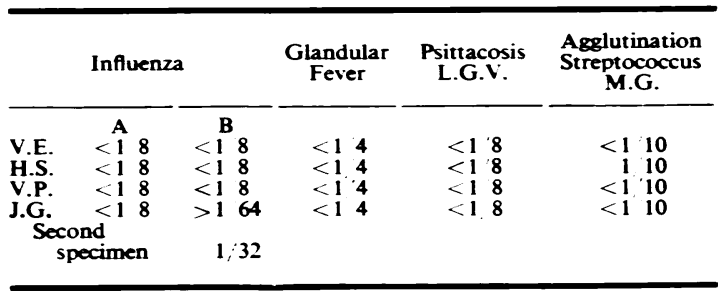

Reference Laboratory at Colindale. Apart from the presence of a titre of 1 in 64 in the influenza B complement fixation test in a specimen from J.G., no significant results were obtained. The full results are listed above.

Local enquiries were made from the Medical Officer of Health, the Superintendent of the City Fever Hospital and from the hospitals in the surrounding towns concerning the prevalence of epidemic disease. There was at the time in question no outbreak of virus pneumonia, glandular fever, poliomyelitis, gastro-enteritis, encephalitis or other unidentified illness which might possibly have been related to the dramatic appearance within 16 days of our four cases of acute acquired haemolytic anaemia.

\section{Discussion}

In this small group of four cases one child responded after one transfusion only and another after transfusion and A.C.T.H. The two remaining children had the spleens removed and were given 
intensive A.C.T.H. therapy. This bears out the difficulty of prognosis in any single case, which is in accordance with the findings of Dameshek and other leading authorities. In Lederer's series (1925, 1930) one patient recovered without transfusion, and the other five with transfusion alone. Dameshek and Schwartz (1940) reviewed about 100 cases, in 66 of which transfusions had been carried out. In 22 of these cases transfusion alone failed to control the haemolysis. They showed that recovery occurred following splenectomy in 20 of 23 cases operated on, 18 of which had been transfused previously without success.

In view of the fact that Dameshek and Rosenthal (1951) obtained satisfactory control of the haemolytic process with A.C.T.H. in certain cases of acute leukaemia, they extended the trial to cases of acute acquired haemolytic anaemia which had failed to respond to transfusion. Ten cases were treated, and of these nine responded satisfactorily. The further reports on this method of treatment which have appeared in the last two years have continued to be favourable, and Dameshek (1952) is now able to report 22 cases, with complete haematological and clinical control in 14 and improvement in six.

Unfortunately, it is necessary to use relatively large doses of A.C.T.H. in these cases (Dameshek and Rosenthal, 1951) and in children, the subject of this paper, it has been difficult to achieve adequate therapeutic dosage without producing toxic effects. In spite of clinical toxic effects, such as undue gain in weight and glycosuria, there was no biochemical or electrocardiographic evidence of electrolyte disturbance. A reliable method of assessing the degree of control of the haemolytic process is required, especially during the period of withdrawal. In view of the very rapid fall in haemoglobin concentration in these children, we found that routine blood counts did not give warning of relapse in time to reinstitute larger dosage before transfusion became necessary. Despite the fact that Clearkin (1952) does not find the Coombs test a reliable guide, we decided to use daily direct Coombs tests in an effort to anticipate acceleration of the haemolytic process. Consideration was given to the possible advantages of the indirect method, but the necessary facilities were not available at the time.

In the two cases which relapsed during the withdrawal period it was decided to resort to splenectomy in view of the large doses of A.C.T.H. which were required, the long duration of the illness, and the necessity for repeated blood transfusions. The operation in each case was performed by Professor D. Chamberlain. Of these two children, V.E. appeared to recover after splenectomy, undertaken during the second course of A.C.T.H., but relapsed on withdrawal of the drug. She subsequently responded to intramuscular cortisone. The other child, J.G., was operated on during a relapse, but failed to maintain a satisfactory haemoglobin level. A further course of A.C.T.H. was successful in controlling the haemolysis, but the Coombs test has remained positive, and it has been necessary to continue therapy with oral cortisone.

\section{Summary}

Four cases of acute acquired haemolytic anaemia in children which presented within a period of 16 days are described, and the possibility of an infective basis for this condition is discussed. The children ranged in age from 6 months to 8 years.

The effects of treatment with A.C.T.H. on the course of the disease are shown, and afford evidence that the underlying abnormal antibody reaction can be controlled if relatively large doses are given.

The place of blood transfusion, splenectomy and A.C.T.H. therapy in clinical management is discussed.

The variable course and progress of the disease, and the need for an individual approach to cases are stressed.

We wish to thank Professor W. S. Craig for his permission to publish details of these cases.

We also wish to thank Dr. J. V. Dacie and the Central Virus Reference Laboratory, Colindale, for their help with agglutination tests, and Mr. C. Sanderson for invaluable help with the frequent Coombs testing required.

\section{ReFERENCES}

Best, $\dot{W}$. R., Limarzi, L. R. and Poncher, H. G. (1951). J. Amer. med. Ass., 147. 827

Chauffard, A.. Troisier, J. and Vincent, C. (1908). Sem. med., B. Aires, 28. 345 .

Clearkin, K. P. (1952). Lancet, 1. 183.

Crary, H. I. and Beck, I. A. (1952). Ann. intern. Med.. 36. 1106.

Dacie, J. V. and Gruchy, G. C. de. (1951). J. clin. Path., 4. 253.

Dameshek, W. (1950). Blond, 5. 79 i.

(1952). Brit. med. J., $2,612$.

and Rosenthal, M. C. (1951). Med. Clin., N. Amer., 35. 1423

— and Rosenthal, M. C. (1951). Med. Clin., N. Amer., 35.1423.

- and Schwartz, S. O. (1940). Medicine, Baltimore, 19. 231.

Davidson, L. S. P.. D sthie, J. J. R., Girdwood, R. H. and Sinclair, R. J. G. (1951). Brit. med. J., 1. 657.

Etess, A. D., Bassen, F., Litwins, J. and Sussman, L. N. (1951). Acta haemat., Basel, 6. 105.

Gardner, F. H. (1950). Blood, 5. 791

McElfresh, A. E., Harris, J. W. and Diamond, L. K. (1951). J. Lab. clin. Med., 37.444.

Hagberg. B. (1952). Acra Soc. Med. upsalien, 56. 273.

Hayem, G. (1908). Bull. Soc. méd. Hóp., Paris, 25. 122.

Langeron, L. (1951). Ibid., 67, 488.

Langeron, L. (1925). Ibid., 170. 500 .

Lederer. M. (1930). Amer. J. med. Sci., 179. 228.

Ley, A. B. and Gardner, F. H. (1951). J. clin. Invest., 30. 656

Mallarmé, J., Martin, Eyquem. Fleury (1951). Sang., 22. 580

Meyer, J. F. (1951). Amer. J. Dis. Child., 82. 721.

Rosenthal, M. C., Spaet. T. H., Goldenberg. H. and Dameshek, W. (1952). Lancet, 1, 1135.

Unger, L. J. (1951). Amer. J. clin. Path., 21. 456.

Widal, F., Abrami, P. and Brule, M. (1907). Presse med., 15, 641

Young, L. E., Christian, R. M. and Izzo. M. J. (1951). Med. Clin. N. Amer., 35, 571 . 